\title{
Influence of Vanadium and Cast Temperature on Nitrogen Solubility of Stainless Steel
}

\author{
Saeed Ghali \\ Central Metallurgical Research \& Development Institute (CMRDI), P.O. Box 87, Helwan, Cairo, Egypt \\ Correspondence should be addressed to Saeed Ghali; a3708052@yahoo.com
}

Received 23 July 2014; Revised 23 October 2014; Accepted 6 November 2014; Published 20 November 2014

Academic Editor: Elena V. Pereloma

Copyright (C) 2014 Saeed Ghali. This is an open access article distributed under the Creative Commons Attribution License, which permits unrestricted use, distribution, and reproduction in any medium, provided the original work is properly cited.

\begin{abstract}
Three stainless steel grades with different vanadium content were produced in open induction furnace. The base chemical composition of investigated stainless steel has contained $18.48-18.75 \% \mathrm{Cr}, 5.17-5.62 \% \mathrm{Mn}, 2.47-2.58 \% \mathrm{Mo}$, and 6.39-6.64\% Ni. The vanadium contents of the three stainless steel grades were $0.009 \%, 0.112 \%$, and $0.189 \%$. The proposed stainless steels were casted at temperatures $1753 \mathrm{~K}$ and $1833 \mathrm{~K}$. The nitrogen contents were determined for the produced steel grades at every cast temperature. The determined nitrogen contents were compared with those calculated from the developed equation of Grigorenko and Pomarin. The influence of cast temperature and vanadium content on nitrogen solubility was investigated. Interpretation between experimental and calculated nitrogen content was carried out. Increasing vanadium content and decreasing cast temperature were found to have positive significant effect on the nitrogen solubility. There were great deviations between experimental results and those calculated by Grigorenko and Pomarin equation.
\end{abstract}

\section{Introduction and Theoretical Aspects}

During the last decades, the importance of nitrogen as an alloying element, especially in austenitic stainless steel, has been a focus of attention of many researchers. As nitrogen is known to be an austenitic stabilizer, in addition to, nickel is partially and totally replaced by nitrogen in austenitic stainless steels [1].

A number of factors that influence the nitrogen solubility in iron alloys are alloy composition, crystal structure, temperature, and the pressure of gaseous nitrogen in the atmosphere above the alloy. An addition of chromium, manganese, and molybdenum to liquid steel increases the nitrogen solubility, while the addition of nickel, carbon, silicon, and copper decreases it [2-7].

At atmospheric pressure the solubility of nitrogen is a function of alloy composition and temperature. Figure 1 is a schematic diagram that illustrates the change of nitrogen solubility with temperature of steel. Where the solubility of nitrogen in ferrite phase is less than in austenite, the temperature of formation of ferrite phase depends on the type of alloying elements and their contents in steel. Therefore, the solubility of nitrogen depends not only on the temperature of molten steel but also on the chemical composition of steel. During cooling, nitrogen solubility increases with decreasing temperature but abruptly decreases just below the solidus due to the formation of bcc $\delta$ ferrite [8-11] as illustrated in Figure 1.

The sudden decrease of nitrogen solubility (solubility gap) may result in pore formation and loss of nitrogen. This problem during solidification has long been a major obstacle in the manufacturing of high nitrogen steel (HNS). To overcome the "solubility gap problem," the nitrogen content of molten iron alloys can be increased beyond the solubility limit at atmospheric pressure by raising the nitrogen partial pressure, that is, melting under pressure using one of the following techniques: pressurized electroslag remelting furnaces (PESR), pressurized induction furnaces (counter pressure casting), plasma arc remelting furnaces (PAR), or arc slag remelting furnaces (ASR) [9-18]. The first two are routinely used among HNS producers worldwide, whereas the last two have found limited applications.

Another way to overcome the "solubility gap" is to use the powder metallurgy route, as the nitrogen solubility in HNS is always higher in the solid phase than in the liquid state. Therefore, instead of adding nitrogen in the liquid state it may 


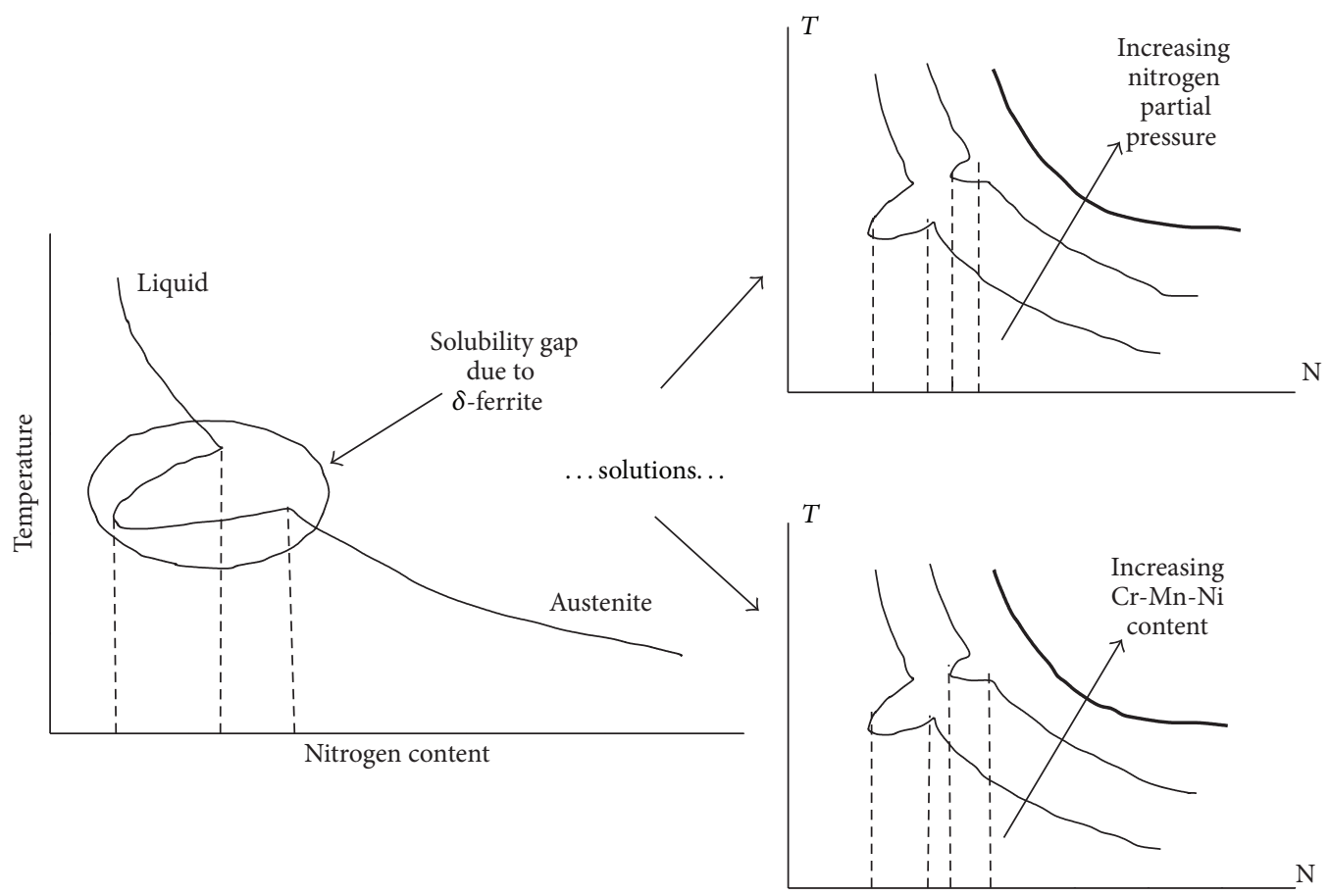

FIGURE 1: Schematic diagram illustrates the behavior of nitrogen with temperature.

be introduced into the steel powder thermally by diffusion or mechanically by milling. However, all these manufacturing routes sound quite "exotic" and "expensive." This can explain why in spite of the good knowledge, accumulated since the end of the 60s, about the favorable effects of nitrogen alloying in austenitic stainless steels, HNS has never been extensively used and adopted in large quantities yet.

This situation is expected to change in the near future if HNS could be made using conventional equipment through increasing the nitrogen solubility at atmospheric pressure and avoiding the "solubility gap" during solidification. This can be done with a careful chemical composition, adding elements with a negative interaction parameter and avoiding those of positive sign. In this way, decreasing nitrogen activity was resulting in an increased solubility by more than two orders of magnitude. This work aims at investigation of the influence of vanadium addition in presence of nearly constant percentages of chromium, manganese, molybdenum on the nitrogen solubility by using conventional melting technique. In addition, the influence of casting temperature on nitrogen solubility will be investigated at different vanadium content.

The formation of vanadium nitrides enables higher nitrogen content in the final solid steels. The nitrogen can be released from nitrides into austenite after heat treatment at certain conditions. Coutsouradis et al [19] have analyzed the solubility data for $\mathrm{VN}$ in austenite at $1050-1100^{\circ} \mathrm{C}$. They used the solubility products of $\mathrm{VN}$ for C-Mn steel. They also found that the presence of $9 \%$ chromium in steel increases the solubility product of vanadium nitride at $1050^{\circ} \mathrm{C}$ approximately nine times and thus raises the amount of $\mathrm{V}$ and $\mathrm{N}$ in solid solution significantly. They deduced that the solubility of $\mathrm{VN}$ at $1050^{\circ} \mathrm{C}$ for $0 \% \mathrm{Cr}$ and $9 \% \mathrm{Cr}$ in $\mathrm{Mn}-\mathrm{C}$ steel containing $0.3 \% \mathrm{~V}$ is less than $0.01 \% \mathrm{~N}$ in solid solution in absence of chromium, while the soluble nitrogen in steel containing $9 \% \mathrm{Cr}$ is more than $0.06 \%$.

\section{Experimental}

Open air induction furnace with capacity $30 \mathrm{~kg}$ was used to produce three grades of stainless steel. The three steel grades have nearly the same chemical composition with different vanadium and nitrogen contents. The cast process was carried out in open air at two different temperatures. The first group of proposed steels was cast at $1753 \mathrm{~K}$ and the second was cast at $1833 \mathrm{~K}$.

Low carbon ferrochromium, low carbon ferromolybdenum, low carbon ferromanganese, and low carbon ferrovanadium were the sources of chromium, molybdenum, manganese, and vanadium, respectively. Ferrochromium bearing nitrogen was the source of nitrogen. Materials were charged into induction furnace in the following sequence: Armco iron, ferrochromium, ferromolybdenum, ferromanganese, nickel metal, and ferrovanadium later. Ferrochromium bearing nitrogen was added to the molten metal after adjusting the temperature, followed by casting process. Molten metal was casted into sand mould in open air. The Kjeldahl method was used to determine total nitrogen in the produced stainless steels.

\section{Results and Discussions}

The chemical composition of the melted stainless steels is given in Table 1. It must be mentioned that the samples taken for analysis were cut from the cast steels. From this table, 
TABLE 1: Chemical compositions of produced stainless steels.

\begin{tabular}{|c|c|c|c|c|c|c|c|c|c|c|c|}
\hline \multirow{2}{*}{ Heat no. } & \multicolumn{10}{|c|}{ Chemical composition, wt.\% } & \multirow{2}{*}{ Cast temp., K } \\
\hline & $\mathrm{C}$ & $\mathrm{Mn}$ & $\mathrm{Si}$ & $\mathrm{Cr}$ & $\mathrm{Ni}$ & Mo & S & $\mathrm{P}$ & $\mathrm{N}$ & $\mathrm{V}$ & \\
\hline \multirow{2}{*}{1} & 0.079 & 5.36 & 1.18 & 18.54 & 6.51 & 2.48 & 0.026 & 0.019 & 0.098 & 0.009 & 1753 \\
\hline & 0.075 & 5.21 & 1.16 & 18.48 & 6.53 & 2.49 & 0.023 & 0.017 & 0.087 & 0.009 & 1833 \\
\hline \multirow{2}{*}{2} & 0.074 & 5.50 & 1.20 & 18.49 & 6.64 & 2.48 & 0.028 & 0.009 & 0.122 & 0.112 & 1753 \\
\hline & 0.071 & 5.39 & 1.21 & 18.53 & 6.39 & 2.47 & 0.028 & 0.007 & 0.098 & 0.112 & 1833 \\
\hline \multirow{2}{*}{3} & 0.082 & 5.62 & 1.19 & 18.75 & 6.55 & 2.55 & 0.021 & 0.018 & 0.143 & 0.189 & 1753 \\
\hline & 0.079 & 5.17 & 1.11 & 18.67 & 6.57 & 2.58 & 0.020 & 0.019 & 0.124 & 0.189 & 1833 \\
\hline
\end{tabular}

it is clear that the base composition of steels is similar for all grades produced. The table also shows the nitrogen and vanadium contents for steel cast at temperatures $1753 \mathrm{~K}$ and $1833 \mathrm{~K}$.

Since the beginning of production high nitrogen stainless steel, there were two main problems, which are how to introduce high nitrogen contents into molten melt and how to keep nitrogen in solid solution during the process of solidification, thus avoiding porosities in cast ingots. To overcome these problems, nitrogen solubility evaluation models in the liquid state and solid state as well as different manufacturing routes were developed. The dissolution of nitrogen in ironbase alloys can be described by the reaction

$$
\frac{1}{2} \mathrm{~N}_{2(\mathrm{~g})} \longleftrightarrow[\mathrm{N}]_{(\mathrm{s})}
$$

where the equilibrium constant for reaction (1) can be written as

$$
\begin{gathered}
K_{\mathrm{N}}=\frac{a_{\mathrm{N}}}{\sqrt{P_{\mathrm{N}_{2}}}}=\frac{f_{\mathrm{N}} \cdot[\% \mathrm{~N}]}{\sqrt{P_{\mathrm{N}_{2}}}}, \\
\log [\% \mathrm{~N}]=\log K_{\mathrm{N}}-\log f_{\mathrm{N}}+\frac{1}{2} \log P_{\mathrm{N}_{2}},
\end{gathered}
$$

where $K_{\mathrm{N}}$ is equilibrium constant of reaction (1), $a_{\mathrm{N}}$ is the activity of nitrogen dissolved in steel, $P_{\mathrm{N}_{2}}$ is the nitrogen partial pressure, $f_{\mathrm{N}}$ is the nitrogen activity coefficient, and $[\% \mathrm{~N}]$ is the nitrogen solubility in weight percent.

From (2), it is clear that nitrogen solubility can be increased through addition of the alloying elements which decrease the nitrogen activity $\left(f_{\mathrm{N}}\right)$ such as $\mathrm{Cr}, \mathrm{Mn}$, and so forth. Several studies about the influence of different alloying elements on the nitrogen solubility in pure iron as well as in multicomponent iron-base materials were carried out [7-10]. Zheng [11] had investigated the basic behavior of the alloying elements and their effect on nitrogen activity coefficient as shown in

$$
\begin{aligned}
\log f_{\mathrm{N}}= & \sum_{i} e_{\mathrm{N}}^{X_{i}} \cdot\left[\% X_{i}\right]+\sum_{i} r_{\mathrm{N}}^{X_{i}} \cdot\left[\% X_{i}\right]^{2} \\
& +\sum_{i, j} r_{\mathrm{N}}^{X_{i}, Y_{j}} \cdot\left[\% X_{i}\right] \cdot\left[\% Y_{j}\right]
\end{aligned}
$$

where $e_{\mathrm{N}}^{X_{i}}$ is first interaction parameter of element $i$ with nitrogen, $r_{\mathrm{N}}^{X_{i}}$ is second interaction parameter of element $i$ with nitrogen, $r_{\mathrm{N}}^{X_{i}, Y_{j}}$ is interaction parameter of elements $i$ and $j$ with nitrogen, and $\left[\% X_{i}\right]$ and $\left[\% Y_{j}\right]$ are weight percent of elements $i$ and $j$, respectively.

But at higher alloy concentrations a linear parameter of interaction is not sufficient and the activity coefficient must be represented in the form of a Taylor series with additional parameters of higher order and parameters describing the combined cross-interaction of two or more alloy components on nitrogen activity. Equation (4) was developed to become as given in (5) [20]. Consider

$$
\begin{aligned}
\log f_{\mathrm{N}}= & \sum_{i=1}^{n} e_{\mathrm{N}}^{i} *[\% i]+\frac{1}{2} \sum_{i=1}^{n} r_{\mathrm{N}}^{i} *[\% i]^{2} \\
& +\frac{1}{6} \sum_{i=1}^{n} q_{\mathrm{N}}^{i} *[\% i]^{3}+\frac{1}{2} \sum_{i=1}^{n-1} q_{\mathrm{N}}^{i, i+1} *[\% i] *[\%(i+1)],
\end{aligned}
$$

where $e_{\mathrm{N}}^{i}$ is first interaction parameter of element $i$ with nitrogen, $r_{\mathrm{N}}^{i}$ is second interaction parameter of element $i$ with nitrogen, $q_{\mathrm{N}}^{i, i+1}$ is interaction parameter of elements $i$ and $(i+1)$ with nitrogen, and $[\% i]$ and $[\%(i+1)]$ are weight percent of elements $i$ and $(i+1)$, respectively.

Grigorenko and Pomarin [20] developed a system based on (5), which is based on a great number of measurements in a wide temperature range up to $2100^{\circ} \mathrm{C}$ and up to high alloying element concentrations, yielding the following:

$$
\begin{aligned}
\log [\% \mathrm{~N}] \\
=-\frac{293}{T}-1.16-\left(\frac{3757}{T}-0.81\right) * \sum e_{\mathrm{N}, 2073 \mathrm{~K}}^{i} *(\% i) \\
-\frac{1}{2}\left(\frac{5132}{T}-1.48\right) * \sum r_{\mathrm{N}, 2073 \mathrm{~K}}^{i} *(\% i)^{2} \\
-\frac{1}{6}\left(\frac{8424}{T}-3.06\right) * \sum q_{\mathrm{N}, 2073 \mathrm{~K}}^{i} *(\% i)^{3}+\frac{1}{2} \log P_{\mathrm{N}_{2}},
\end{aligned}
$$

where $T$ is temperature in $\mathrm{K}, e_{\mathrm{N}, 2073 \mathrm{~K}}^{i}$ is first interaction parameter of element $i$ with nitrogen at $2073 \mathrm{~K}, r_{\mathrm{N}, 2073 \mathrm{~K}}^{i}$ is second interaction parameter of element $i$ with nitrogen at $2073 \mathrm{~K}, q_{\mathrm{N}, 2073 \mathrm{~K}}^{i}$ is third interaction parameter of element $i$ with nitrogen at $2073 \mathrm{~K}$, and $(\% i)$ is weight percent of elements $i$.

Table 2 presents the first, the second, and the third order parameters of interaction for these authors. Based on (6) 
TABLE 2: Interaction parameters in steel melts after Grigorenko and Pomarin [20].

\begin{tabular}{lccc}
\hline Element $(i)$ & $e_{\mathrm{N}}^{i}$ & $2 r_{\mathrm{N}}^{i}$ & $6 q_{\mathrm{N}}^{i}$ \\
\hline $\mathrm{V}$ & $-363 / T+0.080$ & $17.6 / T-0.006$ & $-0.45 / T+0.00018$ \\
$\mathrm{Nb}$ & $-237 / T+0.055$ & $5.14 / T-0.0018$ & $-0.039 / T+0.000012$ \\
$\mathrm{Cr}$ & $-167 / T+0.042$ & $3.3 / T+0.0010$ & \\
$\mathrm{Ta}$ & $-102 / T+0.018$ & $0.80 / T-0.00038$ & \\
$\mathrm{Mn}$ & $-73 / T+0.022$ & \\
$\mathrm{Mo}$ & $-34 / T+0.0061$ & \\
$\mathrm{~W}$ & $-3.6 / T+0.0039$ & \\
$\mathrm{Ni}$ & $-18.4 / T+0.00042$ & & \\
$\mathrm{Si}$ & $171 / T-0.031$ & & \\
$\mathrm{C}$ & $274 / T-0.060$ & & \\
$\mathrm{O}$ & $1640 / T-1.14$ & & \\
$\mathrm{~N}$ & $320 / T-0.12$ & & \\
\hline
\end{tabular}

and interaction parameters as shown in Table 2, the predicted nitrogen contents were calculated at each chemical composition and cast temperature for three steel grades as given in Table 1. The variation between the predicted and the experimental nitrogen content with vanadium content at cast temperature $1753 \mathrm{~K}$ is presented in Figure 2. It is clear that the actual nitrogen contents are greater than the predicted nitrogen contents at different vanadium percentages. There is a little insignificant increment in predicted nitrogen content with increasing vanadium content. However, the experimental results illustrated that there was a clear and tangible increment in nitrogen content with increasing vanadium content. The difference between predicted and actual nitrogen content may occur as a result of one or more of the following parameters.

(i) The interaction coefficients were not sufficiently accurate or insufficient interaction coefficients may have been used.

(ii) The coefficients used were determined from ternary $\mathrm{Fe}-\mathrm{N}-\mathrm{X}$ systems and were assumed to remain the same in complex alloy [6]. This assumption may not hold for the complex alloys studied here.

(iii) The second and third order interaction coefficients have much smaller magnitude than the first and therefore are usually ignored for dilute solutes. For high degree of accuracy, more of them should be included.

(iv) The difference between the actual and predicted nitrogen content may be a result of the melts not reaching equilibrium at target temperature.

Figure 3 illustrates the variation between the predicted and the actual nitrogen content with vanadium percentage at cast temperature $1833 \mathrm{~K}$. Nearly, the same observations were found when cast temperature was $1753 \mathrm{~K}$ with little bit difference in nitrogen contents.

The effect of cast temperature of both predicted and actual nitrogen content is presented in Figure 4. The figure shows that there is a linear relationship between predicted and vanadium content at cast temperatures $1753 \mathrm{~K}$ and $1833 \mathrm{~K}$.

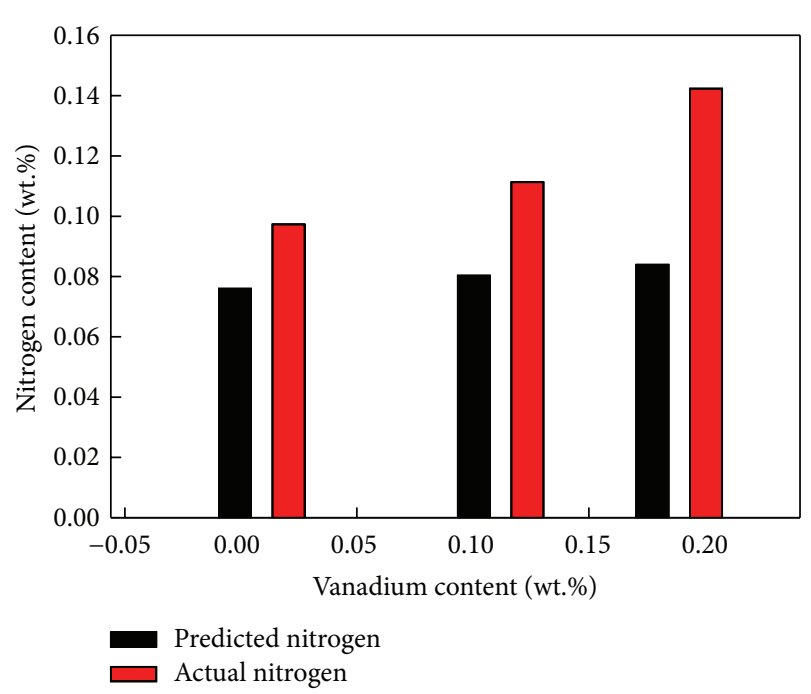

FIGURE 2: The predicted and actual nitrogen content at different vanadium content at cast temperature $1733 \mathrm{~K}$.

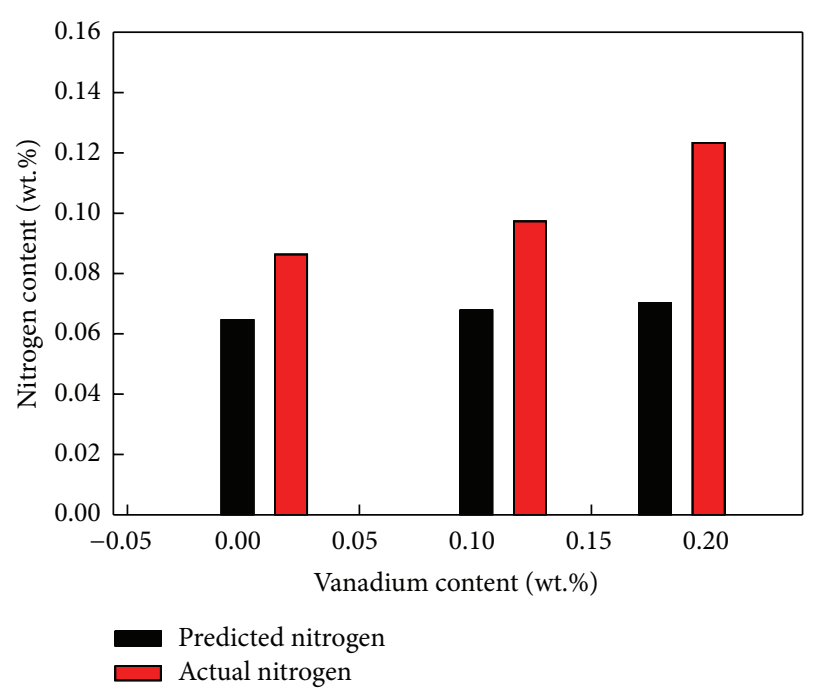

FIGURE 3: The predicted and actual nitrogen content at different vanadium content at cast temperature $1833 \mathrm{~K}$. 


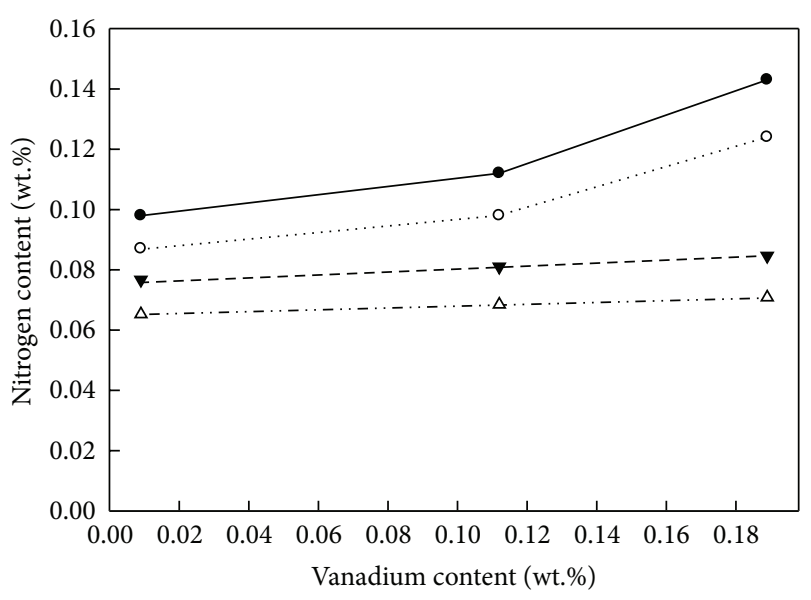

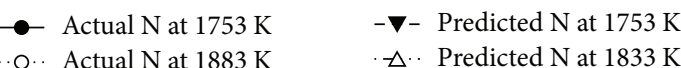

FIGURE 4: The variation between the predicted and the actual nitrogen content with vanadium at temperatures $1753 \mathrm{~K}$ and $1833 \mathrm{~K}$.

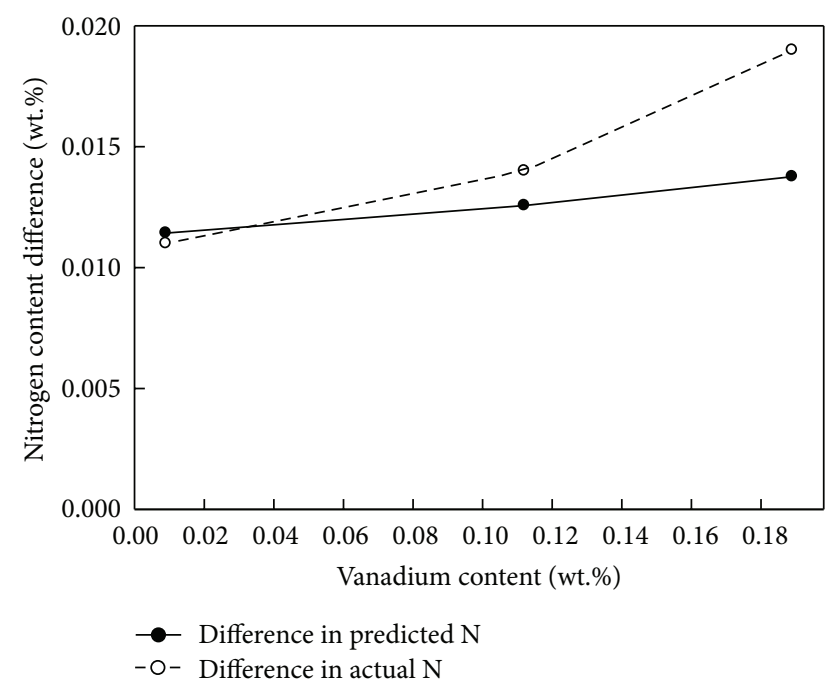

FIGURE 5: Variation of differences in both actual and predicted nitrogen with vanadium at temperatures $1753 \mathrm{~K}$ and $1833 \mathrm{~K}$.

But the relationship between the actual nitrogen content and vanadium content is not linear relationship. Also, it can be noticed that decreasing cast temperature has positive significant effect on nitrogen solubility in both predicted and actual nitrogen content. This may be attributed to the effect of interaction coefficients of alloying elements, which may be changed with temperature.

Figure 5 illustrates the variations between the differences of predicted nitrogen content at temperatures $1753 \mathrm{~K}$ and $1833 \mathrm{~K}$ with vanadium and also the variations between the differences of the actual nitrogen at $1753 \mathrm{~K}$ and $1833 \mathrm{~K}$ with vanadium content. It is clear that the differences of predicted nitrogen at $1753 \mathrm{~K}$ and $1833 \mathrm{~K}$ increase linearly with vanadium content. But the difference of actual nitrogen at $1753 \mathrm{~K}$ and
$1833 \mathrm{~K}$ increases but not linearly, but generally the differences increase by increasing vanadium content. These differences can be attributed to the effect of cast temperature at different vanadium contents. This means that there is an interaction between affecting factors (here are vanadium content and cast temperature).

Vanadium is strong nitride former where it forms nitrides just after solidus line. This means that as cast temperature decreases (at $1753 \mathrm{~K}$ ), the temperature of melt is near to solidus line. The time duration required to reach to solidification is minimized and hence nitrogen escaping from the melt into air decreases. Consequently nitrogen content increases, while at higher temperature (at $1833 \mathrm{~K}$ ) molten steel has more time to reach to its solidus temperature and during this time nitrogen can escape from melt into the air, which leads to lowering nitrogen content in steel.

Therefore the nitrogen content of stainless steels at lower cast temperature is greater than that at higher cast temperature. This may be attributed to the following two opposite factors. The first one is that nitrogen solubility increases by increasing the temperature of molten stainless steels. The second one is that as the temperature of molten stainless steel increases the escaping of nitrogen from molten steel increases and vice versa. So, at higher cast temperature, nitrogen solubility increases but also nitrogen easily and has enough time to escape from the molten stainless steel to reach the equilibrium state. However, at lower temperature, nitrogen has no enough time to escape. So, nitrogen content is relatively high and depends on nitrogen content at cast temperature.

Also, the presence of vanadium causes an increasing in nitrogen solubility as a result of formation of vanadium nitrides. It is noticed that the presence of vanadium reduces the escaping of nitrogen even at higher cast temperature as a result of formation vanadium nitrides; that is, vanadium reduces the activity of nitrogen.

\section{Conclusions}

The nitrogen solubility increases with decreasing cast temperature as a result of the effect of interaction coefficients of alloying elements. Addition of vanadium increases the nitrogen solubility as a result of vanadium nitrides formation just below the liquidus temperature lines. Finally, stainless steel can be produced by conventional metallurgy technique containing nitrogen up to $0.143 \%$ through controlling vanadium content and cast temperature.

The deviations between the actual and predicted nitrogen contents may occur as a result of the insufficient interaction coefficients used or their insufficient accuracy as it was determined from ternary Fe-N-X systems. For higher degree of accuracy the second and the third order interaction coefficients which have been ignored must be included.

\section{Conflict of Interests}

The author declares that there is no conflict of interests regarding the publication of this paper. 


\section{References}

[1] S. N. Ghali, A. Ahmed, M. Eissa, H. El-Faramawy, M. Mishreky, and T. Matta, "Production and application of advanced high nitrogen steel," in International Conference on Science and Technology of Ironmaking and Steelmaking, Jamshedpur, India, December 2013.

[2] H. Wada and R. D. Pehlke, "Nitrogen solution and titanium nitride precipitation in liquid Fe-Cr-Ni alloys," Metallurgical Transactions B, vol. 8, no. 2, pp. 443-450, 1977.

[3] R. D. Pehlke and J. F. Elliott, "Solubility of nitrogen in liquid iron alloys," AIME Transactions, vol. 218, pp. 1088-1101, 1960.

[4] S. N. Ghali, M. M. Eissa, and K. M. El-Fawakhry, "Nitrogen solubility in stainless steels," in Proceedings of the Advances in Theory of Ironmaking and Steelmaking Conference, Department of Materials Engineering, Indian Institute of Science, Bangalore, India, December 2009.

[5] J. Chipman and D. A. Corrigan, "Prediction of the solubility of nitrogen in molten steel," AIME Transactions, vol. 233, pp. 12491252, 1965.

[6] S. N. Ghali, "Low carbon high nitrogen low nickel stainless steel," Steel Research International, vol. 84, no. 5, pp. 450-456, 2013.

[7] Y. M. Pomarin and G. M. Grigorenko, "Equation for the calculation of nitrogen solubility in iron melts," Izvestiya Akademii Nauk SSSR, Metally, no. 4, pp. 40-45, 1989.

[8] C. Kowanda, Stickstofflöslichkeit in Nickel und Nickelbasislegierungen im schmelzflüssigen Zustand unter erhöhtem Stickstoffpartialdruck [Thesis], ETH, 2000.

[9] J. Kunze and I. Rothe, "Solubility of nitrogen in austenitic FeCrMn alloys," Steel Research, vol. 65, no. 8, pp. 331-337, 1994.

[10] E. Schürmann and H. Kunze, “Äquivalente Wirkung von Zusatzelementen auf Löslichkeit, Aktivität und Aktivitätskoeffizienten des Stickstoffs bzw. Schwefels in eisenreichen Drei- und Mehrstofflegierungen bei 1600 Grad C," Giessereiforsschung, vol. 19, 1967.

[11] X. H. Zheng, Nitrogen solubility in iron-base alloys and powder metallurgy of high nitrogen steels [Thesis], ETH, 1991.

[12] H. K. Feichtinger and G. Stein, "Melting of high nitrogen steels," Material Science Forum, vol. 318-320, pp. 261-270, 1999.

[13] B. D. Shanina, V. G. Gavriljuk, H. Berns, and F. Schmalt, "Concept of a new high-strength austenitic stainless steel," Steel Research, vol. 73, no. 3, pp. 105-113, 2002.

[14] M. O. Speidel and P. J. Uggowitzer, "High manganese, high nitrogen austenitic stainless steels: their strength and toughness," in Proceedings of the Two Conferences on High Manganese, High Nitrogen Austenitic Steels, Cincinnati, Ohio, USA, 1987, Chicago, Ill, USA, 1992.

[15] T. Rashev, High Nitrogen Steels, Metallurgy under Pressure, Publishing House of the Bulgarian Academy of Sciences, Sofia, Bulgaria, 1995.

[16] I. Heikkilä and L. Slycke, "Influence of nitrogen alloying on galling properties of pm tool steels," in Proceedings of the 6th International Tooling Conference (ITC '02), J. Bergström, G. Fredriksson, and M. Johansson, Eds., vol. 1, pp. 217-226, Karlstad University, Karlstad, Sweden, 2002.

[17] M. M. Cisneros, H. F. Lopez, H. Mancha, D. Vazauez, E. Valdes, and G. Mendoza, "Development of austenitic nanostructures in high-nitrogen steel powders processed by mechanical alloying," Metallurgical and Materials Transactions A, vol. 33, no. 7, pp. 2139-2144, 2002.
[18] Faculty of Science-Cairo University, Effect of nitrogen as an alloying element on the behavior of stainless steel [Ph.D. thesis], Faculty of Science-Cairo University, Giza, Egypt, 2006.

[19] D. Coutsouradis, J. H. Davidson, J. Ewald et al., Materials for Advanced Power Engineering 1994, part 1, 1994.

[20] G. M. Grigorenko and Y. M. Pomarin, "Nitrogen and hydrogen in molten metals and alloys," in Sov. Tech. Rev. Weld and Surf., vol. 1, pp. 1-63, Naukova Dumka, Harvard Academic Publishers GmbH, GB, Kiev, Ukraine, 1990. 

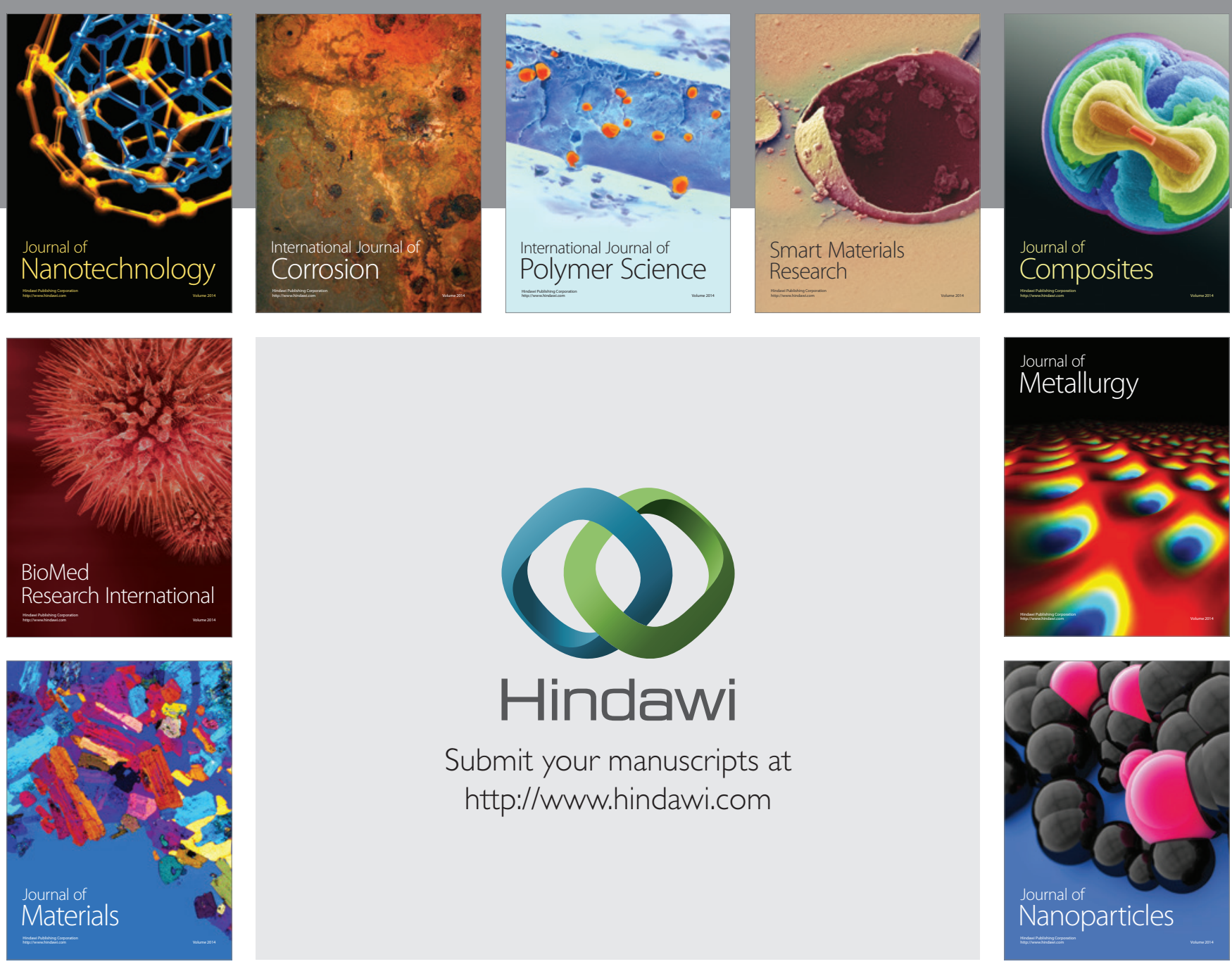

Submit your manuscripts at http://www.hindawi.com
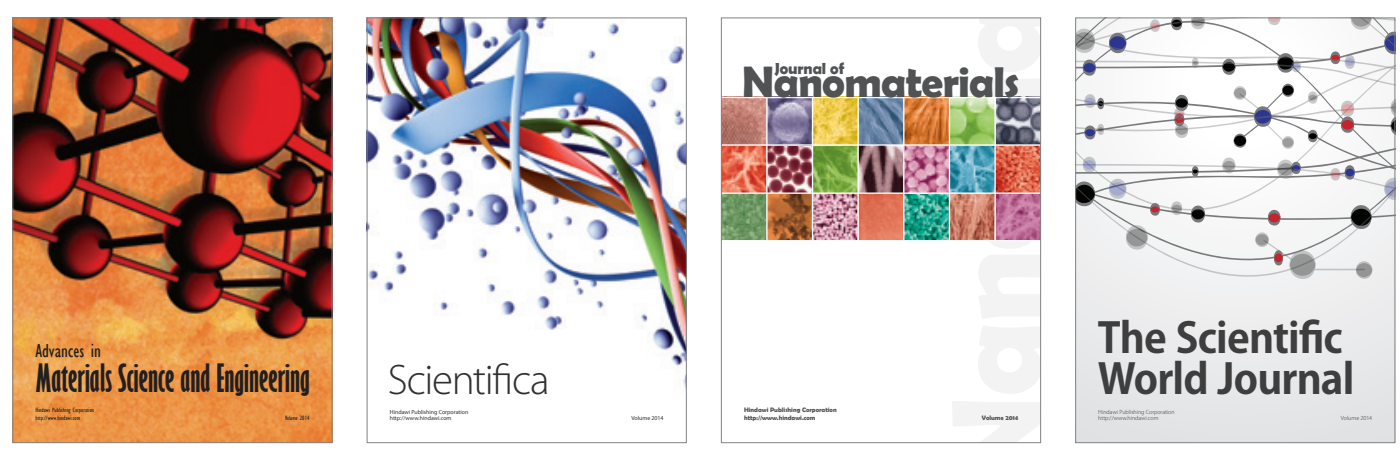

\section{The Scientific World Journal}
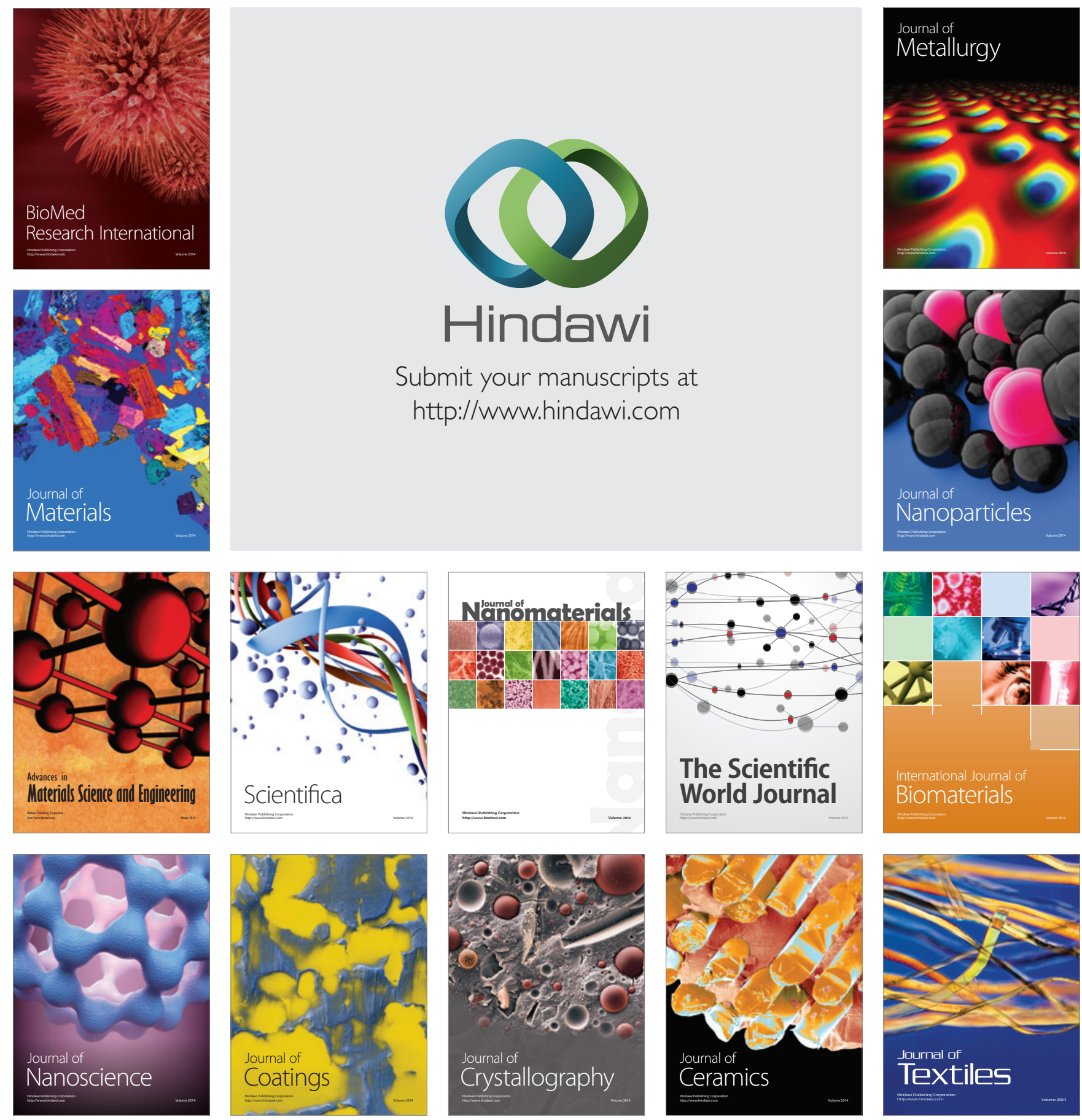